Mini Review

\title{
Epithelial cell restoration and regeneration in inflammatory lung diseases
}

\author{
Seitaro Fujishima*
}

Department of Emergency \& Critical Care Medicine, School of Medicine, Keio University, Tokyo, Japan

Acute lung injury/acute respiratory distress syndrome (ALI/ARDS) is an acute-onset neutrophil-dominant inflammatory lung disease caused by or associated with various illness and injuries. The mortality rate related to this disorder can be as high as $40 \%$. In contrast, idiopathic pulmonary fibrosis/usual interstitial pneumonia (IPF/UIP) is a chronic progressive inflammatory lung disease of unknown etiology, with a mean survival of five years. There are no established treatments for either disease and novel therapies are eagerly desired. Lung epithelial cells were initially discovered to be derived from bone marrow stem cells and progenitor cells. As a result of progress made in regenerative medicine, several types of tissue stem cells and progenitor cells have been identified in the lungs, each of which is involved in tissue repair and regeneration at different levels of the bronchial tree. In terminal bronchioles and alveoli, where lung cells are specifically vulnerable to injuries caused by inflammatory cells, Clara cell-specific protein-positive epithelial cells, including bronchioalveolar stem cells, and a subgroup of alveolar epithelial type II cells, have been identified as lung tissue stem cell and progenitor cell candidates. Intratracheal administration of alveolar epithelial type II cells or epithelial progenitor cells has been shown to be effective in animal models of ALI/ARDS and IPF/UIP. As a novel strategy based on regenerative medicine, this could be a promising approach to treat inflammatory lung diseases.

Rec./Acc.4/11/2011

${ }^{*}$ Correspondence should be addressed to:

Seitaro Fujishima, Department of Emergency and Critical Care Medicine, School of Medicine, Keio University, 35 Shinanomachi, Shinjyuku-ku, Tokyo, 160-8582, Japan.

Key words:

acute lung injury, acute respiratory distress syndrome, idiopathic pulmonary fibrosis, tissue stem cells, inflammatory lung diseases 


\section{Introduction}

Inflammatory lung diseases refers to a group of diseases associated with various types and degrees of inflammatory cell accumulation in the lungs (Table 1). Diseases typically included in this group are acute lung injury/acute respiratory distress syndrome (ALI/ARDS), idiopathic pulmonary fibrosis/usual interstitial pneumonia (IPF/UIP), nonspecific interstitial pneumonia, cryptogenic organizing pneumonia/bronchiolitis obliterans organizing pneumonia, collagen vascular disease-associated interstitial pneumonia, hypersensitivity pneumonitis/extrinsic allergic alveolitis, sarcoidosis, and eosinophilic pneumonia. In a broad sense, chronic obstructive pulmonary disease, bronchial asthma, and infectious diseases can also be included in this list.

Among these illnesses, ALI/ARDS is an acute-onset noncardiogenic or nonhydrostatic pulmonary edema, defined by a $\mathrm{PaO}_{2} / \mathrm{FIO}_{2}$ ratio lower than 300 (ALI) and 200 (ARDS) $)^{1)}$. ALI/ARDS is accompanied or caused by various illness and injuries (Table 2) ${ }^{1,2)}$. Although its pathogenesis is largely undetermined, neutrophil-dominant acute inflammation and resultant tissue destruction are the main pa- thological features. Mortality associated with ALI/ARDS remains as high as $40 \%$, and a novel therapy or therapies are eagerly desired ${ }^{3)}$.

In contrast, IPF/UIP is characterized by diffuse interstitial inflammation of mixed cell types, fibroblast proliferation, and accelerated remodeling of extracellular matrix, which results in irreversible destruction of the lungs ${ }^{4}$. The disease is progressive and often fatal with a mean survival of five years. Although several medications such as glucocorticoids, immunosuppressants, and pirfenidone have resulted in some improvement in a fraction of patients with IPF/UIP, there is no established treatment that reliably improves their prognosis.

Regenerative medicine has made drastic advancements during the last decade, and in addition to bone marrow-derived stem cells and progenitor cells, stem cells and progenitor cells in various organs and tissues have been identified. In the respiratory system, the discovery of several tissue stem cells and progenitor cells, and their roles under physiological and pathological conditions has been clarified. In this short review, lung tissue stem cells and progenitor cells, and their roles in inflammatory lung diseases are summarized.

Table 1. Clinical course and inflammatory cells in inflammatory lung diseases

\begin{tabular}{lll}
\hline Diseases & Clinical Course & Major Inflammatory Cells Observed \\
\hline${ }^{1}$ ALI/ARDS & Acute & Neutrophils \\
\hline${ }^{2}$ IPF/UIP & Chronic/acute exacerbation & Alveolar macrophages, neutrophils? \\
\hline${ }^{3} \mathrm{HP}$ & Acute/chronic & CD8 lymphocytes, (CD4 lymphocytes) \\
\hline Sarcoidosis & Chronic & CD4 lymphocytes \\
\hline${ }^{4} \mathrm{EP}$ & Acute/chronic & Eosinophils \\
\hline${ }^{5} \mathrm{COPD}$ & Chronic/acute exacerbation & CD8 lymphocytes/ neutrophils \\
\hline Asthma & Chronic/acute attack & Eosinophils, basophils, Th2 lymphocytes \\
\hline
\end{tabular}

${ }^{1}$ ALI/ARDS, acute lung injury/acute respiratory distress syndrome; ${ }^{2}$ IPF/UIP, idiopathic pulmonary fibrosis/usual interstitial pneumonia; ${ }^{3} \mathrm{HP}$, hypersensitivity pneumonitis; ${ }^{4} \mathrm{EP}$, eosinophilic pneumonia; ${ }^{5} \mathrm{COPD}$, chronic obstructive pulmonary disease

\section{Lung Stem Cells and Progenitor Cells}

In almost every organism, there exists a compensatory system or systems which replace damaged cells and tissues to maintain physiological functions.
Transdifferentiation of other types of differentiated cells and differentiation of stem cells and progenitor cells are the sources of newly generated cells and tissues, in addition to the proliferation of terminally differentiated cells. However, recent studies have 
revealed that the classical stem cell hierarchy, from stem cells through transient amplifying cells, to terminally differentiated cells, is not always retained, and terminally differentiated cells are capable of becoming facultative stem cells under certain conditions $^{5}$.

Table 2.

Causal or predisposing conditions for acute lung injury/acute respiratory distress syndrome (ALI/ARDS)

\section{Direct Injuries}

1) Toxic inhalation: smoke, toxic chemicals, etc.

2) Drugs and chemicals: Paraquat, morphine, salicylates, bleomycin, amiodarone, etc.

3) Diffuse pulmonary infection: bacterial, viral, rickettsial, fungal, tuberculosis, Pneumocystis jiroveci, malaria, etc.

4) Gastric aspiration, aspiration pneumonia

5) Near-drowning

6) Fat embolism syndrome, amniotic fluid emboli, decompression sickness

7) Pulmonary contusion

8) Thoracic radiation

9) Chronic eosinophilic pneumonia

2. Indirect Injuries

1) Severe sepsis, septic shock

2) Severe non-thoracic trauma

3) Burns

4) Transfusion related acute lung injury (TRALI)

5) Cardiopulmonary bypass (rare)

In the respiratory system, there exist several types of epithelial stem cells and progenitor cells, each of which is involved in tissue repair and regeneration at different levels of the bronchial tree. In the bronchioles of mice, Clara cells, which specifically express Clara cell-specific protein (CCSP), also called secretoglobin 1A1, CC10, or CCA, show characteristics of transient amplifying cells $\mathrm{s}^{6}$. Stripp, et al. reported that naphthalene-resistant variant Clara cells located in bronchioalveolar duct junctions (BADJ) behave as stem cells ${ }^{7}$. In contrast, Kim et al. revealed that CCSP- and surfactant protein C-double-positive epithelial cells almost fully satisfy the phenotype of stem cells and they subsequently named these cells bronchioalveolar stem cells (BASC) $)^{8}$. They further showed that BASCs contribute to the repair of terminal bronchioles as well as alveoli. However, recent data do not support these findings ${ }^{9)}$.

In alveoli, alveolar epithelial type II cells can differentiate into alveolar epithelial type I cells and thus have been considered progenitor cells ${ }^{10)}$. Among alveolar epithelial type II cells, a subgroup of
E-cadherin-negative cells show high telomerase activity, high proliferative potential, and resistance to injurious stimuli, and thus are considered as lung stem cell or progenitor cell candidates ${ }^{11)}$.

On the other hand, CCSP-, SCA-1-, SSEA-1-, and Oct-4-positive cells separated from the lungs of newborn mice have recently been shown to be able to differentiate into alveolar epithelial type I and type II cells, and thus could also be lung stem cell or progenitor cell candidates ${ }^{12)}$. These cells are also specifically infected and damaged by severe acute respiratory syndrome corona virus, suggesting targeted injury of lung stem cells and progenitor cells as a novel etiology for ALI/ARDS.

In addition to the findings in mice, isolation of human lung stem cells has recently been reported by several investigators. Tesei, et al. showed that bronchospheres isolated from human lungs included cells which could differentiate into alveolar epithelial type II cells, Clara cells, and mesenchymal cells ${ }^{13)}$. Fujino, et al. recently reported the successful isolation of populations of alveolar epithelial type II cells from 
adult human lungs ${ }^{14)}$. These observations support the existence of tissue stem cells or progenitor cells in human lungs; however, their roles under physiological and pathological conditions remain to be elucidated.

\section{Bone Marrow-Derived Stem Cells, Progenitor Cells, and Their Contribution to Inflammatory Lung Diseases}

Since Krause et al. showed the differentiation of bone marrow-derived stem cells into lung epithelial cells ${ }^{15}$, there has been a great controversy over the capacity of stem cells and progenitor cells in bone marrow and circulating blood to differentiate into lung cells and their contribution to the maintenance and repair of lung tissues under physiological and pathological conditions. Currently, in addition to bone marrow- and cord blood-derived stem cells, mesenchymal stem cells (MSCs), endothelial progenitor cells (EPCs), and fibrocytes have been shown to differentiate into lung epithelial cells, mesenchymal cells, or endothelial cells. With regard to epithelial cells, CCSP-positive cells in bone marrow were shown to have the capacity to differentiate into alveolar epithelial type I and type II cells ${ }^{16)}$.

Even though lungs are severely damaged as a result of severe pneumonia or ALI/ARDS, lung function of affected patients can sometimes recover to almost normal levels. These findings strongly suggest the active participation of tissue recovery or regeneration mechanisms under these pathological conditions. Moreover, in patients with ALI/ARDS, the number of circulating EPCs was significantly increased, and their induction by some undetermined mediators is assumed ${ }^{17-18)}$. Furthermore, ALI patients with higher numbers of circulating EPCs had better prognoses, suggesting the contribution of EPCs to lung tissue repair in cases of ALI ${ }^{18)}$.

Engraftment of bone marrow-derived stem cells and progenitor cells into repaired lung tissue, and their participation in tissue repair has also been described using animal models of ALI/ARDS. Yamada et al. showed that lipopolysaccharide (LPS) administration induced emphysematous changes in the lungs of radiation-induced bone marrow-suppressed mice ${ }^{19}$. In a mouse model of pneumonia, lineage-negative bone marrow progenitor cells accumulated in the injured lungs ${ }^{20)}$. In a rabbit model of oleic acid-induced ALI, intravascular administration of EPCs ameliorated lung injury ${ }^{21)}$. Furthermore, intratracheal administration of MSCs was shown to ameliorate LPS-induced $\mathrm{ALI}^{22)}$. However, differentiation of MSCs was not essential for therapeutic efficacy, and regulation of inflammation by MSC-derived humoral mediators was thought to be the major mechanisms of action ${ }^{22)}$. In addition, a strategy to use MSCs as a gene vector is being consi$\operatorname{dered}^{23)}$.

\section{Tissue Stem Cells and Progenitor Cells in Inflammatory Lung Disease}

Lung microvascular permeability is mainly regulated by alveolar epithelial cell plasticity, and its normalization is essential for recovery from ALI/ARDS. As mentioned previously, Kim et al. suggested the contribution of BASCs to the repair and regeneration of alveolar epithelial cells following lung injury. However, Rawlin et al. showed contradictory results using an animal model of hyperoxia-induced lung injury ${ }^{9)}$. As the total number of BASCs was shown to be small, they do not seem to play a major role in the recovery of alveoli or terminal bronchioles ${ }^{9,24)}$. However, if we can find methods to actively increasing the number of BASCs, for example by regulating the Gata6-Wnt pathway, which was recently shown to be indispensable for the expansion of BASCs, they will become an attractive therapeutic target. Recently, human embryonic stem cell-derived alveolar epithelial type II cells were shown to abrogate ALI in mice ${ }^{25)}$, revealing embryonic stem cells as candidates for the treatment of inflammatory lung diseases.

With regard to pulmonary fibrosis, epithelial cell injury was shown to induce fibrosis of the lungs ${ }^{26)}$, and matrix metalloproteinases (MMPs), especially MMP-7, are known to be involved in this process ${ }^{27)}$. The role of alveolar epithelial type II cells in lung tissue repair has been the focus of recent investigation once again, and intratracheal administration of isolated epithelial type II cells was shown to improve bleomycin-induced lung fibrosis in rats $^{28)}$. Intratracheal administration of bone marrow-derived lung epithelial progenitors and amniotic epithelial cells was also revealed to attenuate bleomycin-induced lung fibrosis in mice $\mathrm{e}^{29-30)}$. Thus, cell therapy could be a promising approach even for IPF/UIP.

In addition to alveolar epithelial cells, vascular endothelial cell are another major target of extrinsic and intrinsic injurious stimuli. In fact, targeted deletion of forkhead box M1 (FoxM1) in endothelial cells, a key transcription factor involved inr cell proliferation, aggravated LPS-induced lung injury ${ }^{31)}$. 
Accordingly, restoration of endothelial cells, in addition to alveolar epithelial cells, should be included in inflammatory lung disease treatment strategies.

Since the existence of tissue stem cells and progenitor cells in the lungs has been revealed, we are currently examining the mechanisms of tissue recovery and regeneration in mouse models of inflammatory lung diseases and in human lung tissues, using Musashi-1 as a marker of bronchiolar and alveolar epithelial stem cells and progenitor cells.

\section{Concluding Remarks}

It has become clear during the last decade that several types of tissue stem cells and progenitor cells exist at different levels of the bronchial tree and that bone marrow-derived stem cells are also capable of differentiating into lung epithelial cells. In various inflammatory lung diseases, stem cells and progenitor cells, derived from either bone marrow or lung tissue, are mobilized to injured lung tissues, and most likely contribute to the repair and regeneration of the tissue. In patients with severe lung dysfunction as a result of inflammatory lung diseases, intratracheal or intravascular administration of stem cells or progenitor cells could be a promising treatment approach. A potential alternative strategy is to administer endogenous or exogenous mediators that mobilize and activate these cells. Additional extensive research is necessary to actualize these concepts.

\section{Acknowledgement}

I am grateful to Hideyuki Okano, MD, PhD (Department of Physiology, Graduate School of Medicine, Keio University) and Yumi Matsuzaki, MD, $\mathrm{PhD}$ (Center of Integrated Medical Research, Graduate School of Medicine, Keio University) for supporting our research and their helpful discussions.

\section{References}

1) Bernard GR, Artigas A, Brigham KL, Carlet J, Falke K, Hudson L, Lamy M, Legall JR, Morris A, Spragg R: The American-European Consensus Conference on ARDS. Definitions, mechanisms, relevant outcomes, and clinical trial coordination. Am J Respir Crit Care Med. 1994; 149: 818-824.

2) Fraser R, Müller N, Colman N, PD Ps: Fraser and Parré's Diseases of the Chest. 4th edition ed. Philadelphia: W.B. Saunders Company; 1999.

3) Rubenfeld GD, Caldwell E, Peabody E, Weaver J, Martin DP, Neff M, Stern EJ, Hudson LD: Inci- dence and outcomes of acute lung injury. N Engl J Med. 2005; 353: 1685-1693.

4) Gross TJ, Hunninghake GW: Idiopathic pulmonary fibrosis. N Engl J Med. 2001; 345: 517-525.

5) Rawlins EL, Hogan BL: Epithelial stem cells of the lung: privileged few or opportunities for many? Development. 2006; 133: 2455-2465.

6) Stripp BR: Hierarchical organization of lung progenitor cells: is there an adult lung tissue stem cell? Proc Am Thorac Soc. 2008; 5: 695-698.

7) Giangreco A, Reynolds SD, Stripp BR: Terminal bronchioles harbor a unique airway stem cell population that localizes to the bronchoalveolar duct junction. Am J Pathol. 2002; 161: 173-182.

8) Kim CF, Jackson EL, Woolfenden AE, Lawrence S, Babar I, Vogel S, Crowley D, Bronson RT, Jacks T: Identification of bronchioalveolar stem cells in normal lung and lung cancer. Cell. 2005; 121: 823-835.

9) Rawlins EL, Okubo T, Xue Y, Brass DM, Auten RL, Hasegawa H, Wang F, Hogan BL: The role of Scgb1a1+ Clara cells in the long-term maintenance and repair of lung airway, but not alveolar, epithelium. Cell Stem Cell. 2009; 4: 525-534.

10) Fehrenbach H: Alveolar epithelial type II cell: defender of the alveolus revisited. Respir Res. 2001; 2(1): 33-46.

11) Reddy R, Buckley S, Doerken M, Barsky L, Weinberg K, Anderson KD, Warburton D, Driscoll B: Isolation of a putative progenitor subpopulation of alveolar epithelial type 2 cells. Am J Physiol Lung Cell Mol Physiol. 2004; 286: L658-667.

12) Ling TY, Kuo MD, Li CL, Yu AL, Huang YH, Wu TJ, Lin YC, Chen SH, Yu J: Identification of pulmonary Oct-4+ stem/progenitor cells and demonstration of their susceptibility to SARS coronavirus (SARS-CoV) infection in vitro. Proc Natl Acad Sci U S A. 2006; 103: 9530-9535.

13) Tesei A, Zoli W, Arienti C, Storci G, Granato AM, Pasquinelli G, Valente S, Orrico C, Rosetti M, Vannini I, Dubini A, Dell'Amore D, Amadori D, Bonafe M: Isolation of stem/progenitor cells from normal lung tissue of adult humans. Cell Prolif. 2009; 42: 298-308.

14) Fujino N, Kubo H, Suzuki T, Ota C, Hegab AE, He M, Suzuki S, Yamada M, Kondo T, Kato H, Ya- 
maya M: Isolation of alveolar epithelial type II progenitor cells from adult human lungs. Lab Invest. 2011; 91:363-378.

15) Krause DS, Theise ND, Collector MI, Henegariu O, Hwang S, Gardner R, Neutzel S, Sharkis SJ: Multi-organ, multi-lineage engraftment by a single bone marrow-derived stem cell. Cell. 2001; 105: 369-377.

16) Wong AP, Keating A, Lu WY, Duchesneau $P$, Wang X, Sacher A, Hu J, Waddell TK: Identification of a bone marrow-derived epithelial-like population capable of repopulating injured mouse airway epithelium. J Clin Invest. 2009; 119: 336-348.

17) Yamada $M$, Kubo H, Ishizawa $K$, Kobayashi $S$, Shinkawa M, Sasaki H: Increased circulating endothelial progenitor cells in patients with bacterial pneumonia: evidence that bone marrow derived cells contribute to lung repair. Thorax. 2005; 60: 410-413.

18) Burnham EL, Taylor WR, Quyyumi AA, Rojas M, Brigham KL, Moss M: Increased circulating endothelial progenitor cells are associated with survival in acute lung injury. Am J Respir Crit Care Med. 2005; 172: 854-860.

19) Yamada M, Kubo H, Kobayashi S, Ishizawa K, Numasaki M, Ueda S, Suzuki T, Sasaki H: Bone marrow-derived progenitor cells are important for lung repair after lipopolysaccharide-induced lung injury. J Immunol. 2004; 172: 1266-1272.

20) Suzuki H, Hogg JC, van Eeden SF: Sequestration and homing of bone marrow-derived lineage negative progenitor cells in the lung during pneumococcal pneumonia. Respir Res. 2008; 9: 25.

21) Lam CF, Liu YC, Hsu JK, Yeh PA, Su TY, Huang $\mathrm{CC}$, Lin MW, Wu PC, Chang PJ, Tsai YC: Autologous transplantation of endothelial progenitor cells attenuates acute lung injury in rabbits. Anesthesiology. 2008; 108: 392-401.

22) Gupta N, Su X, Popov B, Lee JW, Serikov V, Matthay MA: Intrapulmonary delivery of bone marrow-derived mesenchymal stem cells improves survival and attenuates endotoxin-induced acute lung injury in mice. J Immunol. 2007; 179: 1855-1863.

23) Mei SH, McCarter SD, Deng Y, Parker CH, Liles WC, Stewart DJ: Prevention of LPS-induced acute lung injury in mice by mesenchymal stem cells overexpressing angiopoietin 1. PLoS Med. 2007; 4: e269.
24) Nolen-Walston RD, Kim CF, Mazan MR, Ingenito EP, Gruntman AM, Tsai L, Boston R, Woolfenden AE, Jacks T, Hoffman AM: Cellular kinetics and modeling of bronchioalveolar stem cell response during lung regeneration. Am J Physiol Lung Cell Mol Physiol. 2008; 294: L1158-1165.

25) Wang D, Morales JE, Calame DG, Alcorn JL, Wetsel RA: Transplantation of human embryonic stem cell-derived alveolar epithelial type II cells abrogates acute lung injury in mice. Mol Ther. 2010; 18: 625-634.

26) Sisson TH, Mendez M, Choi K, Subbotina N, Courey A, Cunningham A, Dave A, Engelhardt JF, Liu $\mathrm{X}$, White ES, Thannickal VJ, Moore BB, Christensen PJ, Simon RH: Targeted injury of type II alveolar epithelial cells induces pulmonary fibrosis. Am J Respir Crit Care Med. 2010; 181: 254-263.

27) Fujishima S, Shiomi T, Yamashita S, Yogo Y, Nakano $\mathrm{Y}$, Inoue $\mathrm{T}$, Nakamura M, Tasaka S, Hasegawa N, Aikawa N, Ishizaka A, Okada Y: Production and activation of matrix metalloproteinase 7 (matrilysin 1) in the lungs of patients with idiopathic pulmonary fibrosis. Arch Pathol Lab Med. 2010; 134: 1136-1142.

28) Serrano-Mollar A, Nacher M, Gay-Jordi G, Closa D, Xaubet A, Bulbena O: Intratracheal transplantation of alveolar type II cells reverses bleomycin-induced lung fibrosis. Am J Respir Crit Care Med. 2007; 176: 1261-1268.

29) Germano D, Blyszczuk P, Valaperti A, Kania G, Dirnhofer S, Landmesser U, Luscher TF, Hunziker L, Zulewski H, Eriksson U: Prominin-1/CD133+ lung epithelial progenitors protect from bleomycin-induced pulmonary fibrosis. Am J Respir Crit Care Med. 2009; 179: 939-949.

30) Moodley Y, Ilancheran S, Samuel C, Vaghjiani V, Atienza D, Williams ED, Jenkin G, Wallace E, Trounson A, Manuelpillai U: Human amnion epithelial cell transplantation abrogates lung fibrosis and augments repair. Am J Respir Crit Care Med. 2010; 182: 643-651.

31) Zhao YY, Gao XP, Zhao YD, Mirza MK, Frey RS, Kalinichenko VV, Wang IC, Costa RH, Malik AB: Endothelial cell-restricted disruption of FoxM1 impairs endothelial repair following LPS-induced vascular injury. J Clin Invest. 2006; 116: 2333-2343. 